\title{
Targets of enteric motor neurones: smooth muscle cells
}

\author{
R K Goyal
}

ACOS Research and Development, VA Boston Health Care Center, 1400 VFW

Parkway, West Roxbury, Massachusetts 02132, USA

R K Goyal

Correspondence to: Dr R K Goyal.

raj_goyal@hms.harvard.edu System, VA Medical

The cellular targets of enteric motor neurones are gastrointestinal smooth muscle cells, interstitial cells of Cajal (ICC), motor neurones themselves, neuroendocrine cells, mucosal secretory and absorptive cells, secretory glands, blood vessels, and immune cells. ${ }^{1}$ The effects of motor neurones on smooth muscles, particularly the circular muscle cells and ICCs, are precise in timing whereas their effects on other targets may be somewhat diffuse and long lasting. The enteric motor neurones themselves are targets for intrinsic sensory neurones, enteric interneurones, motor neurones, axons of extrinsic primary afferents, vagal-sacral preganglionic neurones, sympathetic postganglionic neurones, and local and endocrine mediators.

The major physiological neurotransmitters of motor neurones are acetylcholine (ACh), adenosine triphosphate (ATP), tachykinins (substance $\mathrm{P}$ and neurokinin (NK) A), vasoactive intestinal peptide (VIP)-pituitary activating cyclic AMP peptide, and nitric oxide (NO). ${ }^{1}$ Release of neurotransmitter such as ACh is inhibited by presynaptic muscarinic $M_{2}$ receptors, tachykinin $\mathrm{NK}_{2}$ and $\mathrm{NK}_{3}$ receptors, and by NO.

Each of the motor neurotransmitters has a large number of receptor subtypes coupled to a diverse array of intracellular signalling pathways, sometimes producing opposing actions.

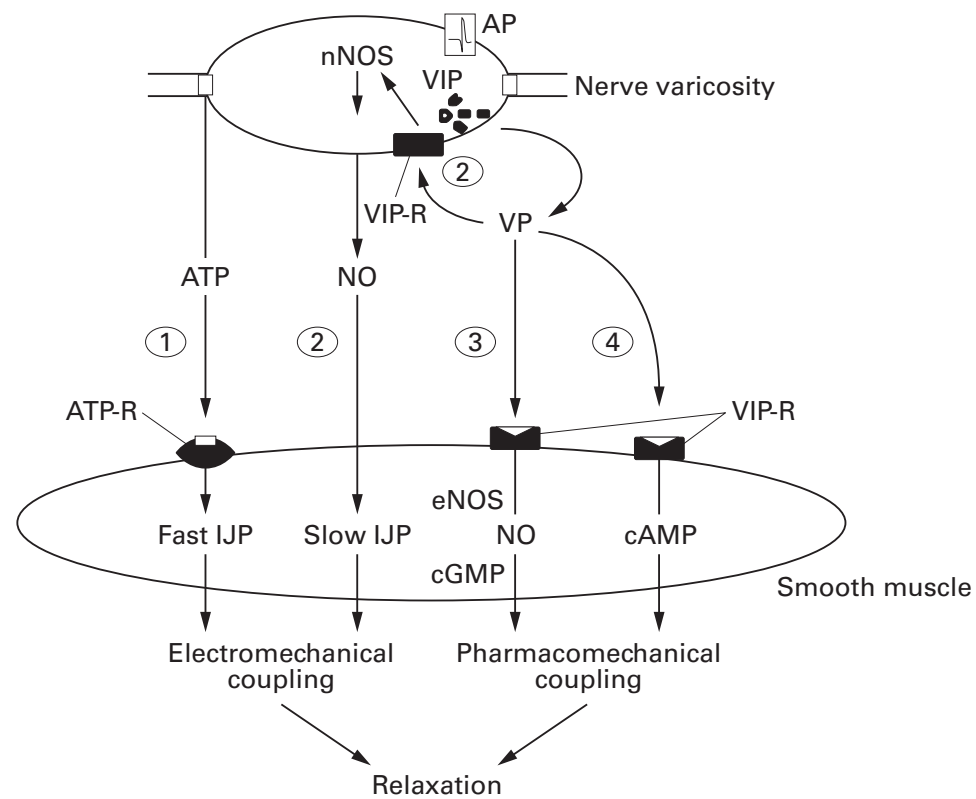

Figure 1 Inhibitory pathways mediating relaxation of smooth muscle. IfP, inhibitory junction potentials; $A T P$, adenosine triphosphate; $A C h$, acetylcholine; $c G M P$, cyclic guanosine monophosphate; $N O$, nitric oxide; NOS, nitric oxide synthase; $A P$, action potential; VIP, vasoactive intestinal peptide; $-R$, receptor.
Some of the important issues related to motor neuromuscular transmissions are:

(1) Differences between the actions of endogenous neurotransmitters and the exogenously administered transmitter candidate.

(2) Regional differences in the actions of motor neurone activation on different tissue layers and different regions of the same tissue layer of the same organ. There are also obvious differences based on organ system and animal species.

(3) In several systems there may be redundancy so that block of one pathway may be compensated for by another parallel pathway serving a similar function.

(4) Finally, during events such as peristalsis, there is a precisely timed sequential activation of inhibitory and excitatory neurones.

The major excitatory motor pathway involves acetylcholine and tachykinins (substance $P$ and NKA) that are frequently colocalised in motor nerve endings. Prejunctional autoreceptors for acetylcholine $\left(\mathrm{M}_{2}\right.$ muscarinic) and $\mathrm{TK}\left(\mathrm{NK}_{2}\right.$ and $\mathrm{NK}_{3}$ ) act to inhibit and therefore limit acetylcholine release. On electrical field stimulation, the cholinergic component of the action starts earlier and lasts for a shorter period of time than the tachykinergic component. The TK responses become more prominent with greater intensities of electrical stimulation. Finally, there are marked regional differences in cholinergic and TK innervation. ${ }^{2}$ Another interesting regional difference shown by cholinergic neurotransmission is the observation that while $\mathrm{M}_{2}$ muscarinic receptor coupled to $G_{i}$ mediates contraction of oesophageal circular muscle, $\mathrm{M}_{3}$ muscarinic receptor coupled to $G_{q / 11}$ mediates contraction of the lower oesophageal sphincter smooth muscle. ${ }^{3}$

The main inhibitory neurotransmitters are ATP, NO, and VIP (fig 1). ${ }^{4}$ The nerve endings that release ATP are not known and nitric oxide synthase (NOS) and VIP are frequently colocalised. Based on their characteristics, two types of inhibitory junction potentials (IJP) can be identified: fast and slow (fig 2). ATP is responsible for fast IJP and the associated mechanical relaxation is mediated via the $P_{2 y}$ purinoreceptor and apamin sensitive small conductance calcium activated potassium channel. ${ }^{67}$ There are marked regional varia-

Abbreviations used in this paper: ICC, interstitial cells of Cajal; IJP, inhibitory junction potentials; ATP, adenosine triphosphate; ACh, acetylcholine; TK, tachykinins; VIP, vasoactive intestinal peptide; NK, neurokinin; NO, nitric oxide; NOS, nitric oxide synthase. 
A

Nitrergic slow IJP

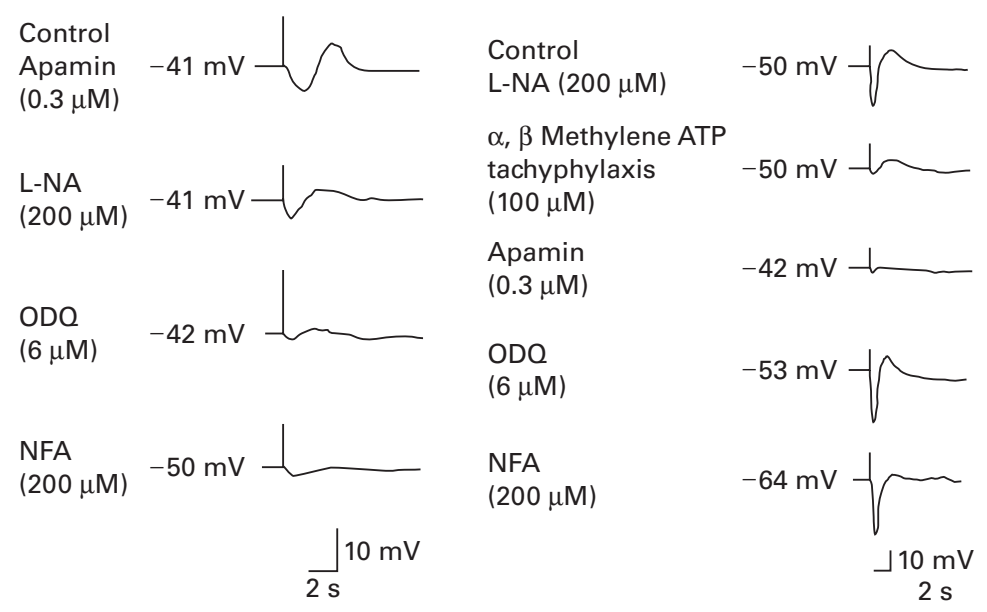

Figure 2 Pharmacology of fast and slow inhibitory junction potentials (IFPs). $L-N A$, $N^{w}$-nitro L-arginine; NFA, niflumic acid; $O D Q, 1$ H-[1,2,4]oxadiazolo[4,3-a]quinoxalin-1-one.

Possible mechanisms for peristalsis

- Sequential activation - Sequential activation

- No preceding
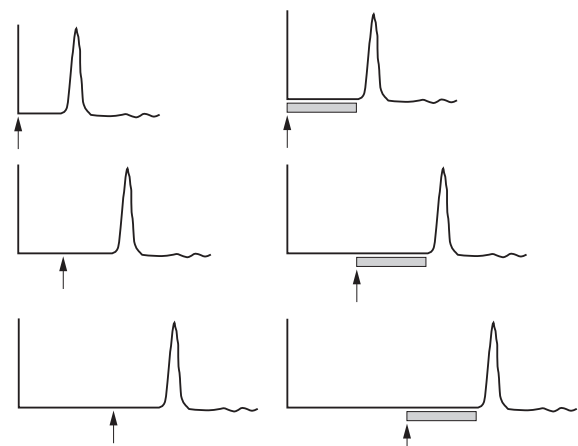
- Inhibition followed by excitation
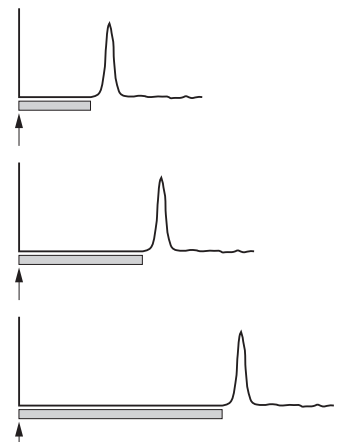

- Simultaneous activation

- Increasing duration of inhibition followed by sequential excitation

Figure 3 Sequence of inhibition and excitation which may explain peristalsis.

tions in the distribution of the purinergic inhibitory pathway. NO ( $\mathrm{NO}^{\circ}$ redox form) derived from neuronal NOS is responsible for the slow IJP. ${ }^{8}$ The nitrergic slow IJP and associated mechanical relaxation is mediated via the cyclic guanosine monophosphate pathway that acts by suppressing resting chloride conductance. ${ }^{9}$ Peptide VIP acts to cause on demand synthesis and release of NO from
NOS containing nerve endings. VIP may also act as a parallel neurotransmitter to cause pharmacomechanically coupled relaxation via the cyclic adenosine monophosphate signalling pathway. ${ }^{10-12}$

In producing peristaltic contractions, the inhibitory and excitatory nerves work together to produce a sequence of inhibition followed by excitation (fig 3). ${ }^{13}$ Activation of inhibitory purinergic nerves (where operative) produces fast inhibition followed by a more prolonged inhibition due to activation of nitrergic nerves. On cessation of activation of the inhibitory nerves, a rebound excitation ensues. Moreover, after activation of the inhibitory nerves is over, excitatory nerves are activated. Excitation due to $\mathrm{ACh}$ and $\mathrm{TK}$ is superimposed on the rebound contraction that results in a contraction wave with cholinergic, tachykinergic, and rebound components. The contribution of these three components may vary depending on the experimental conditions and region of the gut.

1 Goyal RK, Hirano I. The enteric nervous system. $N$ Engl $\mathcal{F}$ Med 1996;334:1106-15.

2 Holzer P, Holzer-Petsche U. Tachykinins in the gut. Part I. Expression release and motor function. Pharmacol Ther 1997;73:173-217.

3 Biancani P, Sohn UD, Rich HG, et al. Signal transduction pathways in esophageal and lower esophageal sphincter circular muscle. Am f Med 1997;103:23-8S.

4 Mashimo H, He XD, Huang PL, et al. Neuronal constitutive nitric oxide synthase is involved in murine enteric nitric oxide synthase is involved in murine enteric
inhibitory neurotransmission. F Clin Invest 1996;98:8-13.

5 Mashimo H, Goyal RK. Lessons from genetically engineered animal models IV. Nitric oxide synthase gene knockout mice. Am f Physiol (Gastrointest Liver Physiol 40) 1999;277:G745-50.

6 Vogalis F, Goyal RK. Activation of small conductance $\mathrm{Ca}^{2+}$ dependent $\mathrm{K}^{+}$channels by purinergic agonists in smooth muscle cells of the mouse ileum. F Physiol 1997;502:497508.

7 Xue L, Farugia G, Sau MG, et al. ATP is a mediator of the fast inhibitory neurotransmitter in gut. Am F Physiol (Gastrointest Liver Physiol 39) 1999;276:G1373-9.

8 Goyal RK, He XD. Evidence for NO redox form of nitric oxide as nitrergic inhibitory neurotransmitter in gut. $A m \mathcal{F}$ oxide as nitrergic inhibitory neurotransmitter in gut. Am $\mathcal{F}$
Physiol (Gastrointest Liver Physiol 38) 1998;275:1 185-92.

9 Zhang Y, Vogalis F, Goyal RK. Nitric oxide suppresses a $\mathrm{Ca}^{2+}$-stumlated $\mathrm{C} 1^{-}$current in smooth muscle cells of opossum esophagus. Am F Physiol (Gastrointest Liver Physiol 27) $1998 ; \mathbf{1 7 2 : 8 8 6 - 9 0}$

10 Takahashi T, Owyang C. Vagal control of nitric oxide and vasoactive intestinal polypeptide release in the regulation of gastric relaxation in the rat. $\mathcal{F}$ Physiol 1995;484:481-92.

11 Pfeifer AP, Klatt S, Massberg L et al. Defective smooth muscle regulation in cGMP kinase I-deficient mice. $E M B O$ f 1998; 17:3045-51.

12 Grider JR, Murthy KS, Jin JG, et al. Stimulation of nitric oxide from muscle cells by VIP: prejunctional enhancement of VIP release. Am $\mathcal{F}$ Physiol 1992;262:G774-8.

13 Goyal RK, Sivarao DV. Functional anatomy and phyiology of swallowiing and esophageal motility. In: Castell DO, Richter JE, eds. The esophagus, 3rd edn. Philadelphia: Lippincott, Williams and Wilkins, 1999:1-31. 